\title{
Disadvantaged families are at greatest risk from austerity cuts to children's centres
}

\author{
James Hall research fellow ${ }^{1}$, Pam Sammons professor of education ${ }^{1}$, Kathy Sylva professor of \\ educational psychology ${ }^{1}$, Maria Evangelou associate professor ${ }^{1}$, Naomi Eisenstadt senior research \\ fellow ${ }^{1}$, Teresa Smith associate fellow ${ }^{2}$, George Smith associate fellow ${ }^{2}$ \\ ${ }^{1}$ Department of Education, University of Oxford, Oxford, UK; ${ }^{2}$ Department of Social Policy and Intervention, University of Oxford, Oxford, UK
}

As authors of the research outlined in your report we were pleased by The BMJ's coverage of our findings on children's centres. ${ }^{1}$ However, we also showed that the threat posed by austerity cuts was even greater in the $20 \%$ most financially disadvantaged families in our sample. ${ }^{2}$

Our report presented three pieces of evidence that support this conclusion:

- Disadvantaged families benefited most when they attended a children's centre that was not implementing cuts. For example, "parent-child dysfunctional interactions" were significantly reduced in centres expanding services rather than making cuts. However, this effect doubled in size when considering only the most disadvantaged (effect size $-0.24 ; \mathrm{P}<0.05)$ rather than all families $(-0.12 ; \mathrm{P}<0.05)$

- The $20 \%$ most disadvantaged families spent more time at their registered children's centre than did more advantaged families

- Disadvantaged families were less likely to use services at locations other than their registered centre.
Referring to your quote from Michael Marmot, "Sure Start children's centres can improve parenting and have a favourable impact on parent-child interactions. The better resourced the centre, the more favourable the impact. Closing these centres, or reducing their funding, is a false economy." Not only do our results support this statement, they also extend it. The better resourced the centre, the more it can narrow gaps linked to poverty and disadvantage.

\section{Competing interests: None declared}

Torjesen I. Austerity cuts are eroding benefits of Sure Start children's centres. BMJ 2016;532:i335. doi:10.1136/bmj.i335. 26785865.

2 Sammons P, Hall J, Smees R, et al. Evaluation of children's centres in England

(ECCE)-strand 4: studying the effects of children's centres in promoting better outcomes for young children and their families. Department for Education. Dec 2015. https://www. gov.uk/government/uploads/system/uploads/attachment_data/file/485346/DFE-RR495 Evaluation_of_children_s_centres_in_England_the_impact_of_children_s_centres.pdf.

Published by the BMJ Publishing Group Limited. For permission to use (where not already granted under a licence) please go to http://group.bmj.com/group/rights-licensing/ permissions 